\title{
Incidence and Predictors of Fragility Fracture in Postmenopausal Rheumatoid Arthritis Patients Receiving Oral Bisphosphonates: A Longitudinal Observational Study
}

Yuji Kishimoto ( $\nabla$ yuji.kish@gmail.com )

Tottori Red Cross Hospital

Yoshihiro Kato

Tottori Red Cross Hospital

Manami Uemura

Tottori Red Cross Hospital

Koji Kuranobu

Tottori Red Cross Hospital

\section{Research Article}

Keywords: bisphosphonate, fracture, osteoporosis, rheumatoid arthritis

Posted Date: August 20th, 2021

DOl: https://doi.org/10.21203/rs.3.rs-809357/v1

License: (c) (i) This work is licensed under a Creative Commons Attribution 4.0 International License. Read Full License

Version of Record: A version of this preprint was published at BMC Rheumatology on February 28th, 2022. See the published version at https://doi.org/10.1186/s41927-021-00243-x. 


\section{Abstract}

Background: Although many studies have reported the predictors of fractures in patients with rheumatoid arthritis (RA) who are not receiving anti-osteoporotic treatments or who are receiving unspecified treatments, studies focusing on the predictors of fracture in patients with RA who are currently being treated with oral bisphosphonates (BP) are quite scarce. This study aims to investigate the incidence and predictors of fragility fracture in postmenopausal patients with RA receiving oral BP.

Methods: This retrospective longitudinal observational study comprised 98 postmenopausal RA patients receiving oral BP for a minimum of 6 months between April 2015 and December 2020. The cumulative incidence of fragility fractures including vertebral and nonvertebral fractures was investigated using the Kaplan-Meier method. Cox proportional hazards analysis was used to analyze baseline predictors of future fragility fractures. To determine a cutoff value of continuous predictors, the receiver-operating characteristic curve was applied.

Results: Twenty patients developed fractures during the study period, with a cumulative incidence of $6.1 \%$ at 12 months, $10.5 \%$ at a median follow-up of 28 months, and $14.4 \%$ at 36 months. Multivariable Cox hazards analysis showed a history of prior vertebral fracture (hazard ratio [HR]: $6.26,95 \%$ confidence interval [Cl]: $1.99-19.68, P=0.001)$ and dose of methotrexate (HR: $0.87,95 \% \mathrm{Cl}: 0.76-0.99, P=0.041)$ to be independent predictors. The cutoff value for methotrexate dose was $4 \mathrm{mg} / \mathrm{week}$.

Conclusions: We found a cumulative incidence of any fractures of $10.5 \%$ at 28 months in patients with RA currently being treated with oral BP. A history of prior vertebral fractures and methotrexate dose were positive and negative predictors for fractures, respectively. Practitioners should consider selecting another anti-osteoporotic drug in patients with RA who remain at risk despite receiving oral BP.

\section{Background}

Rheumatoid arthritis (RA) is a chronic inflammatory disease that is frequently associated with localized and generalized osteoporosis. Previous studies have shown that the incidence of fractures in patients with RA is high [1-3], and although striking improvements have been made in the disease control of RA in recent years, the incidence has not decreased [4]. Osteoporotic fractures are associated with reduced functional status in RA patients [5]. Therefore, in conjunction with tight control of disease activity using disease-modifying antirheumatic drugs (DMARDs), the continuing of anti-osteoporotic treatment is mandatory [6].

Currently, there are various anti-osteoporotic drugs on the market, including oral bisphosphonates (BP), intravenous zoledronic acid, denosumab, teriparatide, and romosozumab in Japan. Among these drugs, oral BP, because of their efficacy and safety combined with low cost, are most commonly used [7] as firstline drugs [8]. Previous studies have concluded that the use of oral BP significantly increased bone mineral density (BMD) [9] and had a protective effect against future fractures in patients with RA [2]. 
In contrast, several studies have reported that switching from BP to another anti-osteoporotic drug, including denosumab $[10,11]$ or teriparatide $[11,12]$, resulted in significant increases in BMD in patients with RA. Furthermore, in patients with glucocorticoid-induced osteoporosis (GIO), incident vertebral fractures were significantly decreased in patients treated with teriparatide as compared with those treated with alendronate [13]. These results suggest that the substitution of a recent anti-osteoporotic drug such as denosumab and teriparatide for oral BP might result in better improvement in BMD and subsequent decreases in future fractures in patients with RA. Therefore, understanding the predictors of fractures is useful when deciding between anti-osteoporotic drugs, to allow identification of patients at risk of future fracture despite receiving oral BP. However, although many studies have reported the predictors of fractures in patients with RA who are not receiving anti-osteoporotic treatments $[14,15]$ or who are receiving unspecified treatments [2,16-18], studies focusing on the predictors of fracture in patients with RA who are currently being treated with oral BP are quite scarce.

The present study aimed to investigate the cumulative incidence of an endpoint defined as the development of fragility fractures in postmenopausal patients with RA who received oral BP for a minimum of 6 months. Furthermore, we also investigated baseline predictors associated with the development of future fragility fractures.

\section{Methods}

\section{Study design and patients}

This was a retrospective longitudinal observational study. All procedures were conducted in accordance with the Declaration of Helsinki and approved by the institutional review board of our institution.

The study population consisted of consecutive patients with RA treated in our hospital between April 2015 and December 2020. All eligible patients fulfilled the inclusion criteria as follows: postmenopausal women aged $\geq 50$ years with RA who met the 2010 American College of Rheumatology/European League Against Rheumatism criteria [19], patients who met our indication of pharmacologic treatment for osteoporosis in patients with RA as described later in this paper, and patients who were newly prescribed oral BP. The exclusion criteria included patients who had previously received a selective estrogen receptor modulator, teriparatide, denosumab, and/or romosozumab; patients who had not continued their prescription of oral BP for more than 6 months; and patients who developed fractures within 6 months from the initiation of oral BP.

\section{Evaluation and indication of pharmacologic treatment for osteoporosis}

In the osteoporosis evaluation, participants were asked about their history of fractures and underwent thoracic and lumbar spine radiologic examination as well as dual X-ray absorptiometry (DXA) at the hip and spine. We initiated pharmacologic treatment with oral BP for osteoporosis in patients with RA who met any one of the following criteria, in this order: (1) history of a fragility fracture at the vertebra and/or 
proximal femur, (2) T-score $<-2.5$ of BMD at the lumbar spine and/or total hip as measured by DXA, and (3) fulfilling the Japanese Society of Osteoporosis criteria for the diagnosis of GIO [20]. We defined fragility fractures as a bone fracture resulting from a fall from standing height or lower or without any trauma. We performed DXA scans using a Hologic QDR2000 scanner (Hologic Inc., Waltham, MA, USA).

\section{Oral BP prescription}

We prescribed either alendronate, risedronate, or minodronate as oral BP. The selection of oral BP was based on the discretion of the attending rheumatologist. We took the following measures to ensure adherence to oral BP. First, we preferentially selected monthly or weekly oral BP over daily oral BP [21, 22]. Second, at the initiation of oral BP, patients received an individual face-to-face educational meeting with a Certified Nurse by Japan Rheumatism Foundation (M.U.) and received a booklet that contained general information regarding osteoporosis. Third, patients provided a self-reported recall of adherence at each visit.

\section{Diagnosis of fragility fractures}

After the patient began taking oral BP agents, we monitored for the development of subsequent fragility fractures. We diagnosed symptomatic fragility fractures when the patient experienced an acute increase in pain as a result of a fall from standing height or lower with radiologic evidence of fractures.

Furthermore, to evaluate asymptomatic subsequent vertebral fractures, we obtained thoracic and lumbar spine radiographs every 6 to 12 months after the initiation of oral BP until the final follow-up. We defined asymptomatic vertebral fractures as a new fracture with a decrease of $\geq 20 \%$ in any vertebral height from baseline [23].

\section{Potential predictors}

In the present study, we determined potential predictors of fragility fractures based on the existing knowledge of predictors of fractures in patients with RA (such as age $[2,16,17]$, body mass index [14, 17], disease duration [14], history of prior fracture $[2,16]$, disease activity $[15,16]$, functional impairment [16, 17], rheumatoid factor [15], daily oral glucocorticoid [16, 18], and BMD of the spine and hip [14, 15]) at baseline. Furthermore, we also included potential predictors of osteoporosis in patients with RA (such as anti-citrullinated peptide antibody [24], methotrexate [25, 26], and biological DMARDs [27]) as well as thorough discussions with attending physicians specializing in rheumatology (such as vitamin $D$ supplementation and type of oral BP).

To evaluate the patients' history of prior vertebral fracture, we obtained thoracic and lumbar spine radiographs at baseline. We did not include history of prior nonvertebral fracture, as only three patients confirmed this history. Disease activity and functional impairment were estimated using the Simplified Disease Activity Index (SDAI) and the Health Assessment Questionnaire Disability Index (HAQ-DI), respectively. Rheumatoid factor and anti-citrullinated peptide antibody were evaluated based on both their positivity and titers. We evaluated oral glucocorticoid and methotrexate based on whether the patient was taking these as well as the patient's daily and weekly dose, respectively. We assessed the use 
of biological DMARDs and vitamin D supplementation by whether the patient was taking these at baseline.

\section{Statistical analyses}

To estimate the cumulative incidence of any fragility fracture after the prescription of oral BP, we performed Kaplan-Meier analyses, and the comparison was performed by log-rank test, with a $P$ value of $<.05$ considered statistically significant. Observations were right-censored the last date at which thoracic and lumbar spine radiography was conducted, if fractures had not developed clinically or radiologically. We presented the cumulative incidence as the percentage and $95 \%$ confidence intervals (Cls).

We used the Cox proportional hazards model to estimate the hazard ratios (HRs) of predictors related to fragility fractures by univariate and multivariate analyses. Because the calculation of large numbers of variables on a limited number of patients might lead to overfitting, we selected variables for the identification of a useful, restricted subset of variables for predictors related to fragility fractures. First, we applied the univariate analyses, and if a variable had a $P$ value of $<.05$ in the univariate analyses, we used it in the multivariate analysis. In the multivariate analysis, all variables with a $P$ value of $<.05$ were considered statistically significant and as independent predictors. For a continuous variable detected as an independent predictor, we used the receiver-operating characteristic (ROC) curve to determine a cutoff value for predicting the development of any fragility fracture. The point closest to the upper left-hand corner of the graph was chosen as the cutoff value.

We conducted statistical analyses using R, version 3.4.1 (The R Foundation for Statistical Computing, Vienna, Austria).

\section{Results}

\section{Patient characteristics}

A total of 105 postmenopausal women aged $\geq 50$ years with RA fulfilled the inclusion criteria of this study. Of these 105 patients, 7 were excluded: 4 had previously received selective estrogen receptor modulator and 3 were prescribed oral BP for less than 6 months. Finally, we included 98 patients in the present study. Of these 98 patients, 28 were prescribed oral BP for a history of fragility fracture, 61 were for a T-score $<-2.5$ of BMD, and 9 were for fulfilling the diagnosis of $\mathrm{GIO}$ in terms of the indication of pharmacologic treatment for osteoporosis.

Table 1 displays the characteristics of the 98 patients, including demographic and clinical variables and medication use at the time of oral BP initiation (baseline). The median (interquartile range) patient age at baseline was 69 (65-74) years. The median duration of disease was 80 (8-209) months, the SDAl was $6.80(3.83-12.00)$, and the HAQ-DI was $0.50(0.13-1.13)$. Twenty-seven $(27.6 \%)$ patients had a history of prior vertebral fractures. Methotrexate was concomitantly administered in $79.6 \%$ of patients with a 
median dose of $6 \mathrm{mg} /$ week, whereas oral glucocorticoid was concomitantly administered in $50.0 \%$ of the patients with a median dose of $0.2 \mathrm{mg} /$ day. The methotrexate dose in the present study was comparable with that used in recent multicenter observational studies performed in Japan [28, 29]. Seventy-two (73.5\%) patients were prescribed monthly oral BP, and $26(26.5 \%)$ were prescribed weekly oral BP. The median follow-up from the initiation of oral BP was $28(11-45)$ months. 
Table 1

Patient characteristics at baseline

\begin{tabular}{|c|c|c|c|}
\hline Parameter & $\begin{array}{l}\text { Total } \\
(n=98)\end{array}$ & $\begin{array}{l}\text { Fractured } \\
(n=20)\end{array}$ & $\begin{array}{l}\text { Non-fractured } \\
(n=78)\end{array}$ \\
\hline Age (years old) & $69(65-74)$ & $71(67-75)$ & $69(65-74)$ \\
\hline $\mathrm{BMI}\left(\mathrm{kg} / \mathrm{m}^{2}\right)$ & $20.4(18.7-22.9)$ & $20.1(17.8-21.2)$ & $20.5(19.0-23.4)$ \\
\hline Disease duration (months) & $80(8-209)$ & $180(56-270)$ & $63(6-162)$ \\
\hline History of vertebral fracture, $\mathrm{n}(\%)$ & $27(27.6)$ & $14(70.0)$ & $13(16.7)$ \\
\hline SDAI & $\begin{array}{l}6.80(3.83- \\
12.00)\end{array}$ & $\begin{array}{l}7.24(4.70- \\
11.87)\end{array}$ & $6.73(3.72-12.00)$ \\
\hline HAQ-DI & $0.50(0.13-1.13)$ & $1.00(0.50-1.63)$ & $0.44(0.13-1.00)$ \\
\hline Rheumatoid factor positive, $\mathrm{n}(\%)$ & $72(73.5)$ & $16(80.0)$ & $56(71.8)$ \\
\hline Rheumatoid factor (IU/mL) & $45(14-89)$ & $41(23-80)$ & $45(14-89)$ \\
\hline ACPA positive, $n(\%)$ & $75(76.5)$ & $16(80.0)$ & $59(75.6)$ \\
\hline ACPA $(U / m L)$ & $25(5-250)$ & $33(8-366)$ & $35(3-234)$ \\
\hline $\mathrm{CRP}(\mathrm{mg} / \mathrm{dL})$ & $0.18(0.04-0.67)$ & $0.09(0.01-0.83)$ & $0.19(0.05-0.58)$ \\
\hline $\begin{array}{l}\text { Concomitant oral glucocorticoid, } n \\
(\%)\end{array}$ & $49(50.0)$ & $13(65.0)$ & $36(46.1)$ \\
\hline Dose of oral glucocorticoid (mg/day) & $0.2(0-3.8)$ & $2.5(0-3.0)$ & $0(0-5.0)$ \\
\hline Concomitant methotrexate, $\mathrm{n}(\%)$ & $78(79.6)$ & $16(80.0)$ & $62(79.5)$ \\
\hline Dose of methotrexate (mg/week) & $6(0-8)$ & $4.0(0-8.0)$ & $8.0(2.5-8.0)$ \\
\hline Concomitant bDMARDs, n (\%) & $33(33.7)$ & $9(45.0)$ & $24(30.8)$ \\
\hline Lumbar BMD $\left(\mathrm{g} / \mathrm{cm}^{2}\right)$ & $0.73(0.66-0.82)$ & $0.73(0.63-0.83)$ & $0.73(0.66-0.81)$ \\
\hline Total hip BMD $\left(\mathrm{g} / \mathrm{cm}^{2}\right)$ & $0.62(0.56-0.68)$ & $0.56(0.50-0.65)$ & $0.62(0.58-0.68)$ \\
\hline Vitamin D supplementation, $\mathrm{n}(\%)$ & $27(27.6)$ & $3(15.0)$ & $24(30.8)$ \\
\hline Type of oral BP, $\mathrm{n}(\%)$ & & & \\
\hline
\end{tabular}

BMI, body mass index; SDAI, Simplified Disease Activity Index; HAQ-DI, Health Assessment Questionnaire Disability Index; ACPA, anticyclic citrullinated protein antibodies; CRP, C-reactive protein; bDMARDs, biological disease-modifying antirheumatic drugs; BMD, bone mineral density; BP, bisphosphonates.

Continuous variables were presented as the median with interquartile range, and categorical variables were presented as numbers with percentages. 


\begin{tabular}{|llll|}
\hline Parameter & $\begin{array}{l}\text { Total } \\
(\mathbf{n = 9 8 )}\end{array}$ & $\begin{array}{l}\text { Fractured } \\
(\mathbf{n = 2 0 )}\end{array}$ & $\begin{array}{l}\text { Non-fractured } \\
\mathbf{( n = 7 8 )}\end{array}$ \\
\hline Alendronate & $14(14.3)$ & $5(25.0)$ & $9(11.5)$ \\
\hline Risedronate & $24(24.5)$ & $6(30.0)$ & $18(23.1)$ \\
\hline Minodronate & $60(61.2)$ & $9(45.0)$ & $51(65.4)$ \\
\hline $\begin{array}{l}\text { BMI, body mass index; SDAl, Simplified Disease Activity Index; HAQ-DI, Health Assessment } \\
\text { Questionnaire Disability Index; ACPA, anticyclic citrullinated protein antibodies; CRP, C-reactive protein; } \\
\text { bDMARDs, biological disease-modifying antirheumatic drugs; BMD, bone mineral density; BP, } \\
\text { bisphosphonates. }\end{array}$ & \\
\hline $\begin{array}{l}\text { Continuous variables were presented as the median with interquartile range, and categorical variables } \\
\text { were presented as numbers with percentages. }\end{array}$ \\
\hline
\end{tabular}

\section{Cumulative incidence of fragility fracture}

During the study period, 20 of 98 patients developed fragility fractures. Fracture regions included the vertebrae in nine patients, the distal forearm in four patients, the proximal humerus in three patients, the femoral neck in two patients, and pelvis and rib in one patient each. Figure 1 presents the cumulative incidence of fragility fractures, which was $6.1 \%$ (95\% Cl: $0.8-11.1)$ at 12 months, $10.5 \%$ (95\% Cl: 3.317.2) at a median follow-up of 28 months, and $16.8 \%(95 \% \mathrm{Cl}: 6.8-25.8)$ at 36 months after initiation of oral BP.

\section{Predictors for fragility fracture}

Table 2 shows the results of the univariate and multivariable Cox proportional hazards analyses for fragility fractures. The univariate Cox proportional hazards analysis identified a history of prior vertebral fracture (HR: 5.67, 95\% Cl: 2.17-14.79, $P<0.001$ ), HAQ-DI (HR: 1.91, 95\% Cl: 1.10-3.31, $P=0.020$ ), concomitant oral glucocorticoid use (HR: 2.52, 95\% Cl: 1.00-6.37, $P=0.049$ ), and dose of methotrexate (HR: $0.82,95 \% \mathrm{Cl}: 0.73-0.92, P<0.001$ ) as significant factors associated with the development of fragility fractures. Using the above-mentioned four significant factors from the univariate analysis, the multivariable Cox proportional hazards analysis showed that prior vertebral fracture was an independent positive predictor (HR: $6.26,95 \% \mathrm{Cl}: 1.99-19.68, P=0.001$ ) and that methotrexate dose was a significant negative predictor (HR: $0.87,95 \% \mathrm{Cl}: 0.76-0.99, P=0.041$ ) for fragility fractures in postmenopausal patients with RA receiving oral BP. 
Table 2

Results of univariate and multivariate Cox proportional hazards analyses for fragility fractures in postmenopausal patients with rheumatoid arthritis receiving oral bisphosphonates.

\begin{tabular}{|c|c|c|c|c|c|c|}
\hline \multirow[b]{2}{*}{ variables } & \multicolumn{3}{|c|}{ Univariable regression } & \multicolumn{3}{|c|}{ Multivariable regression } \\
\hline & $H R$ & $95 \% \mathrm{Cl}$ & $\begin{array}{l}P \\
\text { value }\end{array}$ & $\mathrm{HR}$ & $95 \% \mathrm{Cl}$ & $\begin{array}{l}P \\
\text { value }\end{array}$ \\
\hline Age & 1.01 & $0.95-1.07$ & .661 & & & \\
\hline BMI & 0.96 & $0.82-1.14$ & .716 & & & \\
\hline Disease duration & 1.00 & $0.99-1.00$ & .117 & & & \\
\hline History of vertebral fracture & 5.67 & $\begin{array}{l}2.17- \\
14.79\end{array}$ & $<.001$ & 6.26 & $\begin{array}{l}1.99- \\
19.68\end{array}$ & .001 \\
\hline SDAl & 0.98 & $0.92-1.04$ & .519 & & & \\
\hline HAQ-DI & 1.91 & $1.10-3.31$ & .020 & 1.34 & $0.74-2.45$ & .325 \\
\hline Rheumatoid factor positive & 2.51 & $0.81-7.07$ & .107 & & & \\
\hline Rheumatoid factor titer & 1.00 & $0.99-1.00$ & .900 & & & \\
\hline ACPA positive & 1.76 & $0.57-5.40$ & .323 & & & \\
\hline ACPA titer & 1.00 & $0.99-1.00$ & .398 & & & \\
\hline CRP & 1.12 & $0.71-1.75$ & .621 & & & \\
\hline $\begin{array}{l}\text { Concomitant oral } \\
\text { glucocorticoid }\end{array}$ & 2.52 & $1.00-6.37$ & .049 & 2.02 & $0.70-5.81$ & .190 \\
\hline Dose of oral glucocorticoid & 1.10 & $0.93-1.29$ & .255 & & & \\
\hline Concomitant methotrexate & 0.34 & $0.11-1.05$ & .061 & & & \\
\hline Dose of methotrexate & 0.82 & $0.73-0.92$ & $<.001$ & 0.87 & $0.76-0.99$ & .041 \\
\hline Concomitant bDMARDs & 1.61 & $0.65-3.98$ & .297 & & & \\
\hline Lumbar BMD & 0.48 & $\begin{array}{l}0.00- \\
28.29\end{array}$ & .724 & & & \\
\hline Total hip BMD & 0.01 & $0.00-3.19$ & .104 & & & \\
\hline Vitamin D supplementation & 0.56 & $0.16-1.96$ & .371 & & & \\
\hline Minodronate & 0.56 & $0.18-1.64$ & .303 & & & \\
\hline
\end{tabular}

$\mathrm{HR}$, hazard ratio; $95 \% \mathrm{Cl}, 95 \%$ confidence interval; BMI, body mass index; SDAl, Simplified Disease Activity Index; HAQ-DI, Health Assessment Questionnaire Disability Index; ACPA, anticyclic citrullinated protein antibodies; CRP, C-reactive protein; bDMARDs, biological disease-modifying antirheumatic drugs; BMD, bone mineral density. 
Risedronate

$0.70 \quad 0.21-2.36 \quad .575$

HR, hazard ratio; 95\% Cl, 95\% confidence interval; BMI, body mass index; SDAl, Simplified Disease Activity Index; HAQ-DI, Health Assessment Questionnaire Disability Index; ACPA, anticyclic citrullinated protein antibodies; CRP, C-reactive protein; bDMARDs, biological disease-modifying antirheumatic drugs; BMD, bone mineral density.

To evaluate the cutoff value of the continuous predictor, the dose of methotrexate, we performed ROC analysis (Fig. 2). The area under the curve was 0.61 (95\% Cl: 0.47-0.75). A cutoff value of $4 \mathrm{mg} /$ week was determined by the point closest to the upper left-hand corner of the graph with a sensitivity and specificity of $55.0 \%$ and $70.5 \%$, respectively.

\section{Subgroup analysis between patients with or without predictors for fragility fractures}

Based on the assessment of predictors for fragility fractures, we performed subgroup analysis for the cumulative incidence of any fragility fracture. The cumulative incidence at 28 months in patients who had an absence $(n=71)$ and presence $(n=27)$ of a history of prior vertebral fracture was $2.1 \%(95 \% \mathrm{Cl}$ : $0-11.4)$ and $30.8 \%$ (95\% Cl: 8.6-47.6), respectively ( $P<0.001$; Fig. 3a). At 28 months, the cumulative incidence in patients prescribed $>4 \mathrm{mg} /$ week $(n=64)$ and $\leq 4 \mathrm{mg} /$ week $(n=34)$ dose of methotrexate was $8.0 \%$ (95\% Cl: $0.1-15.2)$ and $14.8 \%(95 \% \mathrm{Cl}: 0.3-27.2)$, respectively $(P<0.001$; Fig. $3 \mathrm{~b})$.

Considering a history of prior vertebral fracture and $\leq 4 \mathrm{mg} /$ week dose of methotrexate to be risk factors for future fragility fracture, patients were categorized into three groups based on the number of risk factors they had: $0(n=49), 1(n=37)$, and $2(n=12)$. The cumulative incidence of any fragility fracture at 28 months in patients with 0,1 , and 2 risk factors was $2.7 \%$ (95\% Cl: $0-8.0), 12.0 \%$ (95\% Cl: $0-24.1)$, and 40.0\% (95\% Cl: 0.4-63.8), respectively ( $P<0.001$; Fig. 3c).

\section{Discussion}

In this study, we investigated the incidence and predictors of fragility fractures in postmenopausal patients with RA who were prescribed oral BP. The cumulative incidence of fragility fracture was $10.5 \%$ at a median follow-up of 28 months. We found that a history of prior vertebral fracture and methotrexate dose were positive and negative predictors, respectively, of the development of future fragility fractures. The cutoff dose of methotrexate for future fragility fracture was $4 \mathrm{mg} /$ week. The cumulative incidence of fragility fracture in the patients with both risk factors, a history of prior vertebral fracture and $\leq 4$ $\mathrm{mg} /$ week dose of methotrexate, was significantly higher than the patients without risk factors.

There are only scarce studies investigating the mid- to long-term incidence of fractures in patients with RA receiving anti-osteoporotic medication (including oral BP). Kwon et al. reported a 3-year fracture incidence of $17.4 \%$ in Asian patients with RA aged 50 years or older from a nationwide claim database, 
with no mention of osteoporosis treatment [30]. Katayama et al. reported that $12.5 \%$ of patients older than 50 years old with RA who were prescribed alendronate developed vertebral or nonvertebral fracture during an average follow-up period of 32.8 months [31]. Taking into consideration our result of a $10.5 \%$ cumulative incidence of fracture at 28 months, we observed a certain degree of fracture prevention effect, however, some patients with RA are still at risk, even if they are receiving oral BP. Other new antiosteoporotic drugs have recently become available, such as denosumab and teriparatide, which probably have better fracture prevention effects in patients with RA [10-12]. However, initiating treatment with these recent anti-osteoporotic drugs in all RA patients is very likely to be too costly; therefore, it is important to select patients at risk despite the prescription of oral BP.

In the present study, we identified a history of prior vertebral fracture as a positive predictor of fragility fractures. A systematic review on osteoporosis concluded that a history of prior fracture was an important risk factor for future fractures [32]. Furthermore, several previous studies found that in patients with RA, a history of prior fracture was a risk factor for incident fractures $[2,16,33]$ with or without antiosteoporotic medications. Our results suggest that in postmenopausal RA patients, a history of vertebral fracture is a strong predictor of fragility fractures, even among those who are taking oral BP medication.

In the present study, we found that the dose of methotrexate was a negative predictor and a dose of $\leq 4$ $\mathrm{mg} /$ week dose was a risk factor for future fragility fractures. We suggest that there are two possible reasons why the outcome of methotrexate dose is a negative predictor. First, one of the reasons for restricting the dose of methotrexate is associated renal dysfunction that increases the incidence of any fracture risk [34]. Renal dysfunction in patients receiving no or low-dose methotrexate might affect the development of fragility fractures; however, we did not include an assessment of renal function in the present study. Second, previous studies reported that a combination of methotrexate and BP prevented systemic bone loss in an in vivo animal model of arthritis [35,36] as well as in patients with RA [37]. There is a need for future clinical investigations to determine whether the combination of methotrexate and BP can decrease the development of fragility fractures.

The present study had several limitations. First, this was a retrospective longitudinal study limited by the use of data collected from patient charts. We did not evaluate any factors that might have affected the development of fragility fracture, such as renal dysfunction, smoking, alcohol intake or the Fracture Risk Assessment Tool score. However, we included almost every factor correlated with fragility fractures in patients with RA, as reported in previous studies. Second, in the present study, we treated alendronate, risedronate, and minodronate identically to oral BP. Several previous studies reported that these medications had different efficacy in patients with RA [31,38,39]. Thus, the type of oral BP might affect the outcome. However, in the univariate Cox regression analysis, we did not find the type of oral BP to be a statistically significant factor. Third, we took several measures to ensure medication adherence, but no specific instrument was used to assess adherence to oral BP. Finally, this was a single-center study with a small population of patients. Thus, our results on the predictors for fragility fractures should be interpreted with caution. Larger, multicenter studies are warranted to obtain greater accuracy and generalizability of the study findings. 
The present study investigated the incidence and predictors of fragility fractures in postmenopausal women with RA associated with osteoporosis who is receiving oral BP. We found a cumulative incidence of any fragility fractures of $10.5 \%$ at a median follow-up of 28 months. A history of prior vertebral fractures was a positive predictor, whereas the dose of methotrexate was a negative predictor of the development of fragility fractures. Practitioners should consider selecting another anti-osteoporotic drug in patients with RA who remain at risk despite receiving oral BP.

\section{Abbreviations}

BMI body mass index

BP bisphosphonates

$\mathrm{Cl}$ confidence interval

DMARD disease-modifying antirheumatic drug

DXA dual X-ray absorptiometry

GIO glucocorticoid-induced osteoporosis

HAQ-DI Health Assessment Questionnaire Disability Index

HR hazard ratio

RA rheumatoid arthritis

ROC receiver-operating characteristic

SDAI Simplified Disease Activity Index

\section{Declarations}

\section{Ethics approval and consent to participate}

The study was approved by the institutional review board of study institution (IRB number: 254, Tottori Red Cross Hospital, Tottori, Japan) and written informed consent was obtained from all participants.

Consent for publication

Not applicable.

Availability of data and materials 
The datasets during and/or analyzed during the current study available from the corresponding author on reasonable request.

Competing interests

The authors declare that they have no competing interests.

\section{Funding}

This research did not receive any specific grant from funding agencies in the public, commercial, or notfor-profit sectors.

\section{Authors' contributions}

YKi: Conceptualization, Methodology, Formal analysis, Investigation, Writing - Original Draft, Project administration. YKa: Formal analysis, Data Curation. MU: Investigation. KK: Investigation, Writing Review and Editing.

\section{Acknowledgements}

The authors would like to thank Enago (www.enago.jp) for their English language review.

\section{References}

1. Xue AL, Wu SY, Jiang L, Feng AM, Guo HF, Zhao P. Bone fracture risk in patients with rheumatoid arthritis: A meta-analysis. Medicine (Baltimore). 2017;96:e6983.

2. Kim D, Cho SK, Choi CB, Jun JB, Kim TH, Lee HS, et al. Incidence and risk factors of fractures in patients with rheumatoid arthritis: an Asian prospective cohort study. Rheumatol Int. 2016;36:120514.

3. Vis M, Haavardsholm EA, Boyesen P, Haugeberg G, Uhlig T, Hoff M, et al. High incidence of vertebral and non-vertebral fractures in the OSTRA cohort study: a 5-year follow-up study in postmenopausal women with rheumatoid arthritis. Osteoporos Int. 2011;22:2413-9.

4. Ochi K, Inoue E, Furuya T, Ikari K, Toyama Y, Taniguchi A, et al. Ten-year incidences of self-reported non-vertebral fractures in Japanese patients with rheumatoid arthritis: discrepancy between disease activity control and the incidence of non-vertebral fracture. Osteoporos Int. 2015;26:961-8.

5. Omata Y, Hagiwara F, Nishino J, Matsudaira K, Kadono Y, Juji T, et al. Vertebral fractures affect functional status in postmenopausal rheumatoid arthritis patients. J Bone Miner Metab. 2014;32:725-31.

6. Baillet A, Gossec L, Carmona L, Wit M, van Eijk-Hustings $Y$, Bertheussen $H$, et al. Points to consider for reporting, screening for and preventing selected comorbidities in chronic inflammatory rheumatic diseases in daily practice: a EULAR initiative. Ann Rheum Dis. 2016;75:965-73. 
7. Hoes JN, Bultink IE, Lems WF. Management of osteoporosis in rheumatoid arthritis patients. Expert Opin Pharmacother. 2015;16:559-71.

8. Raterman HG, Bultink IEM, Lems WF. Current Treatments and New Developments in the Management of Glucocorticoid-induced Osteoporosis. Drugs. 2019;79:1065-87.

9. Tada M, Inui K, Sugioka Y, Mamoto K, Okano T, Anno S, et al. Use of bisphosphonate might be important to improve bone mineral density in patients with rheumatoid arthritis even under tight control: the TOMORROW study. Rheumatol Int. 2017;37:999-1005.

10. Kaneko T, Okamura K, Yonemoto Y, Okura C, Suto T, Tachibana M, et al. Effects of denosumab on bone mineral density and bone turnover markers in rheumatoid arthritis patients switching from bisphosphonates. J Exp Orthop. 2019;6:41.

11. Ebina K, Hirao M, Hashimoto J, Hagihara K, Kashii M, Kitaguchi K, et al. Assessment of the effects of switching oral bisphosphonates to denosumab or daily teriparatide in patients with rheumatoid arthritis. J Bone Miner Metab. 2018;36:478-87.

12. Ebina K, Hashimoto J, Shi K, Kashii M, Hirao M, Yoshikawa H. Comparison of the effect of 18-month daily teriparatide administration on patients with rheumatoid arthritis and postmenopausal osteoporosis patients. Osteoporos Int. 2014;25:2755-65.

13. Saag KG, Shane E, Boonen S, Marín F, Donley DW, Taylor KA, et al. Teriparatide or alendronate in glucocorticoid-induced osteoporosis. N Engl J Med. 2007;357:2028-39.

14. El Maghraoui A, Rezqi A, Mounach A, Achemlal L, Bezza A, Ghozlani I. Prevalence and risk factors of vertebral fractures in women with rheumatoid arthritis using vertebral fracture assessment. Rheumatology (Oxford). 2010;49:1303-10.

15. Filho JC, Pinheiro MM, de Moura Castro CH, Szejnfeld VL. Prevalence and risk factors associated with low-impact fractures in men with rheumatoid arthritis. Clin Rheumatol. 2014;33:1389-95.

16. Ishida O, Furuya T, Inoue E, Ochi K, Ikari K, Taniguchi A, et al. Risk factors for established vertebral fractures in Japanese patients with rheumatoid arthritis: Results from a large prospective observational cohort study. Mod Rheumatol. 2015;25:373-8.

17. Furuya T, Inoue E, Hosoi T, Taniguchi A, Momohara S, Yamanaka H. Risk factors associated with the occurrence of hip fracture in Japanese patients with rheumatoid arthritis: a prospective observational cohort study. Osteoporos Int. 2013;24:1257-65.

18. Furuya T, Kotake S, Inoue E, Nanke Y, Yago T, Hara M, et al. Risk factors associated with incident fractures in Japanese men with rheumatoid arthritis: a prospective observational cohort study. $J$ Bone Miner Metab. 2008;26:499-505.

19. Aletaha D, Neogi T, Silman AJ, Funovits J, Felson DT, Bingham CO, 3rd, et al. 2010 Rheumatoid arthritis classification criteria: an American College of Rheumatology/European League Against Rheumatism collaborative initiative. Arthritis Rheum. 2010;62:2569-81.

20. Suzuki Y, Nawata H, Soen S, Fujiwara S, Nakayama H, Tanaka I, et al. Guidelines on the management and treatment of glucocorticoid-induced osteoporosis of the Japanese Society for Bone and Mineral Research: 2014 update. J Bone Miner Metab. 2014;32:337-50. 
21. Papaioannou A, Kennedy CC, Dolovich L, Lau E, Adachi JD. Patient adherence to osteoporosis medications: problems, consequences and management strategies. Drugs Aging. 2007;24:37-55.

22. Kishimoto $\mathrm{H}$, Maehara M. Compliance and persistence with daily, weekly, and monthly bisphosphonates for osteoporosis in Japan: analysis of data from the CISA. Arch Osteoporos. 2015;10:231.

23. Black DM, Schwartz AV, Ensrud KE, Cauley JA, Levis S, Quandt SA, et al. Effects of continuing or stopping alendronate after 5 years of treatment: the Fracture Intervention Trial Long-term Extension (FLEX): a randomized trial. JAMA. 2006;296:2927-38.

24. Guler $H$, Turhanoglu AD, Ozer B, Ozer C, Balci A. The relationship between anti-cyclic citrullinated peptide and bone mineral density and radiographic damage in patients with rheumatoid arthritis. Scand J Rheumatol. 2008;37:337-42.

25. Buckley LM, Leib ES, Cartularo KS, Vacek PM, Cooper SM. Effects of low dose methotrexate on the bone mineral density of patients with rheumatoid arthritis. J Rheumatol. 1997;24:1489-94.

26. Torikai E, Kageyama Y, Takahashi M, Nagano A. The effect of methotrexate on bone metabolism markers in patients with rheumatoid arthritis. Mod Rheumatol. 2006;16:350-4.

27. Siu S, Haraoui B, Bissonnette R, Bessette L, Roubille C, Richer V, et al. Meta-analysis of tumor necrosis factor inhibitors and glucocorticoids on bone density in rheumatoid arthritis and ankylosing spondylitis trials. Arthritis Care Res (Hoboken). 2015;67:754-64.

28. Fukuda W, Hanyu T, Katayama M, Mizuki S, Okada A, Miyata M, et al. Risk stratification and clinical course of hepatitis $B$ virus reactivation in rheumatoid arthritis patients with resolved infection: final report of a multicenter prospective observational study at Japanese Red Cross Hospital. Arthritis Res Ther. 2019;21:255.

29. Oguro N, Yajima N, Miwa Y. Age and quality of life in patients with rheumatoid arthritis treated with biologic agents. Mod Rheumatol. 2020;30:44-9.

30. Kwon HY, Kim HH, Sung YK, Ha YC. Incidence and Mortality of Osteoporotic Fracture in Rheumatoid Arthritis in South Korea Using Nationwide Claims Data. J Bone Metab. 2019;26:97-104.

31. Katayama K, Matsuno T. Effects of bisphosphonates on fracture incidence and bone metabolism in rheumatoid arthritis patients in general practice taking long-term corticosteroid therapy: a retrospective study. Clin Drug Investig. 2008;28:149-58.

32. Klotzbuecher CM, Ross PD, Landsman PB, Abbott TA, 3rd, Berger M. Patients with prior fractures have an increased risk of future fractures: a summary of the literature and statistical synthesis. $J$ Bone Miner Res. 2000;15:721-39.

33. van Staa TP, Geusens P, Bijlsma JW, Leufkens HG, Cooper C. Clinical assessment of the long-term risk of fracture in patients with rheumatoid arthritis. Arthritis Rheum. 2006;54:3104-12.

34. Chen H, Lips P, Vervloet MG, van Schoor NM, de Jongh RT. Association of renal function with bone mineral density and fracture risk in the Longitudinal Aging Study Amsterdam. Osteoporos Int. 2018;29:2129-38. 
35. Xie Z, Liu G, Tang P, Sun X, Chen S, Qin A, et al. Bone-targeted methotrexate-alendronate conjugate inhibits osteoclastogenesis in vitro and prevents bone loss and inflammation of collagen-induced arthritis in vivo. Drug Deliv. 2018;25:187-97.

36. Le Goff B, Soltner E, Charrier C, Maugars Y, Redini F, Heymann D, et al. A combination of methotrexate and zoledronic acid prevents bone erosions and systemic bone mass loss in collagen induced arthritis. Arthritis Res Ther. 2009;11:R185.

37. Xie J, Li S, Xiao L, Ouyang G, Zheng L, Gu Y, et al. Zoledronic acid ameliorates the effects of secondary osteoporosis in rheumatoid arthritis patients. J Orthop Surg Res. 2019;14:421.

38. Ebina K, Noguchi T, Hirao M, Hashimoto J, Kaneshiro S, Yukioka M, et al. Effects of switching weekly alendronate or risedronate to monthly minodronate in patients with rheumatoid arthritis: a 12-month prospective study. Osteoporos Int. 2016;27:351-9.

39. Kumagai K, Harigane K, Kusayama Y, Tezuka T, Inaba Y, Saito T. Total knee arthroplasty improves both knee function and disease activity in patients with rheumatoid arthritis. Mod Rheumatol. 2017;27:806-10.

\section{Figures}




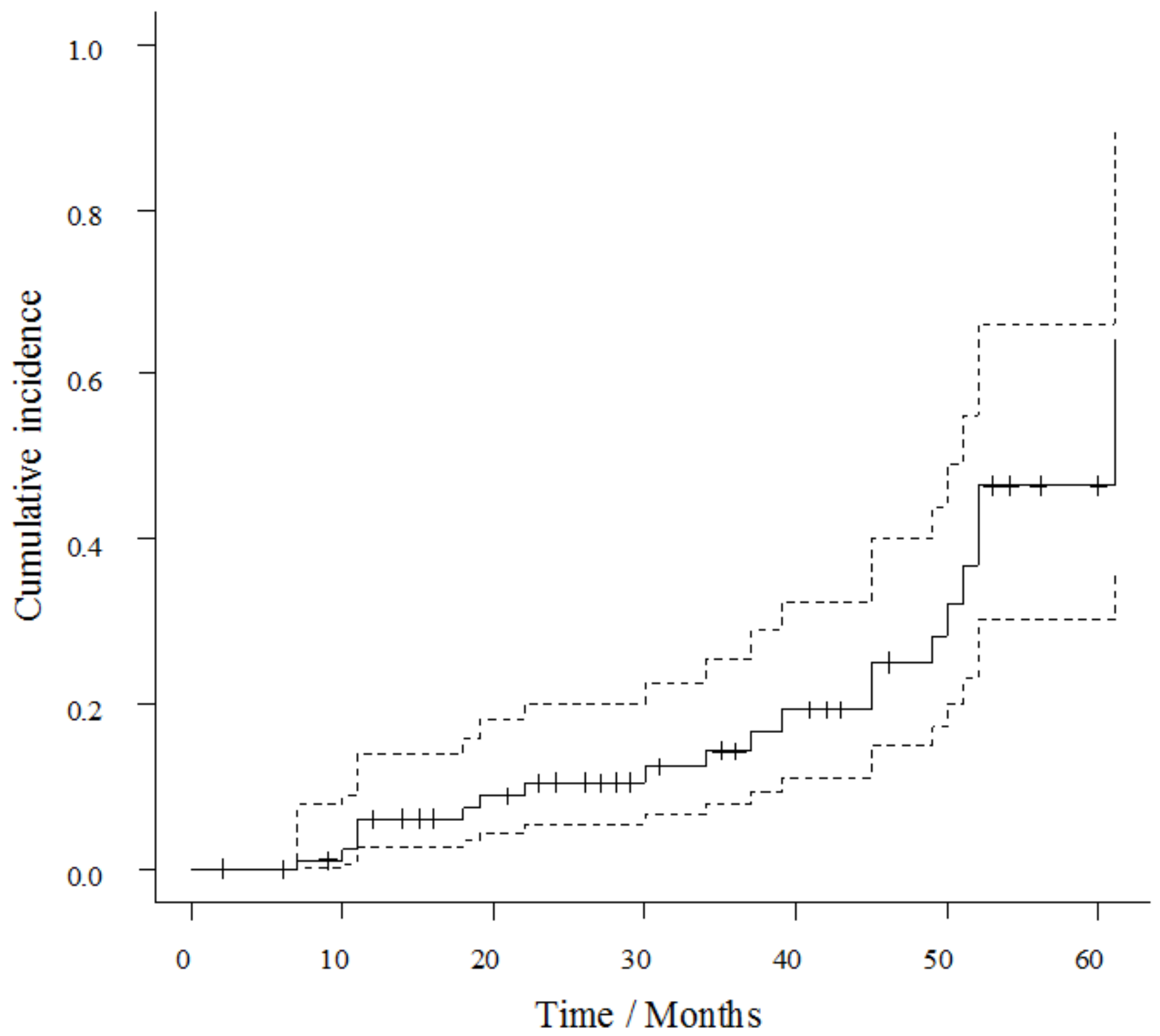

Figure 1

Cumulative incidence curve with $95 \%$ confidence intervals for the endpoint defined as the development of any fragility fractures. 


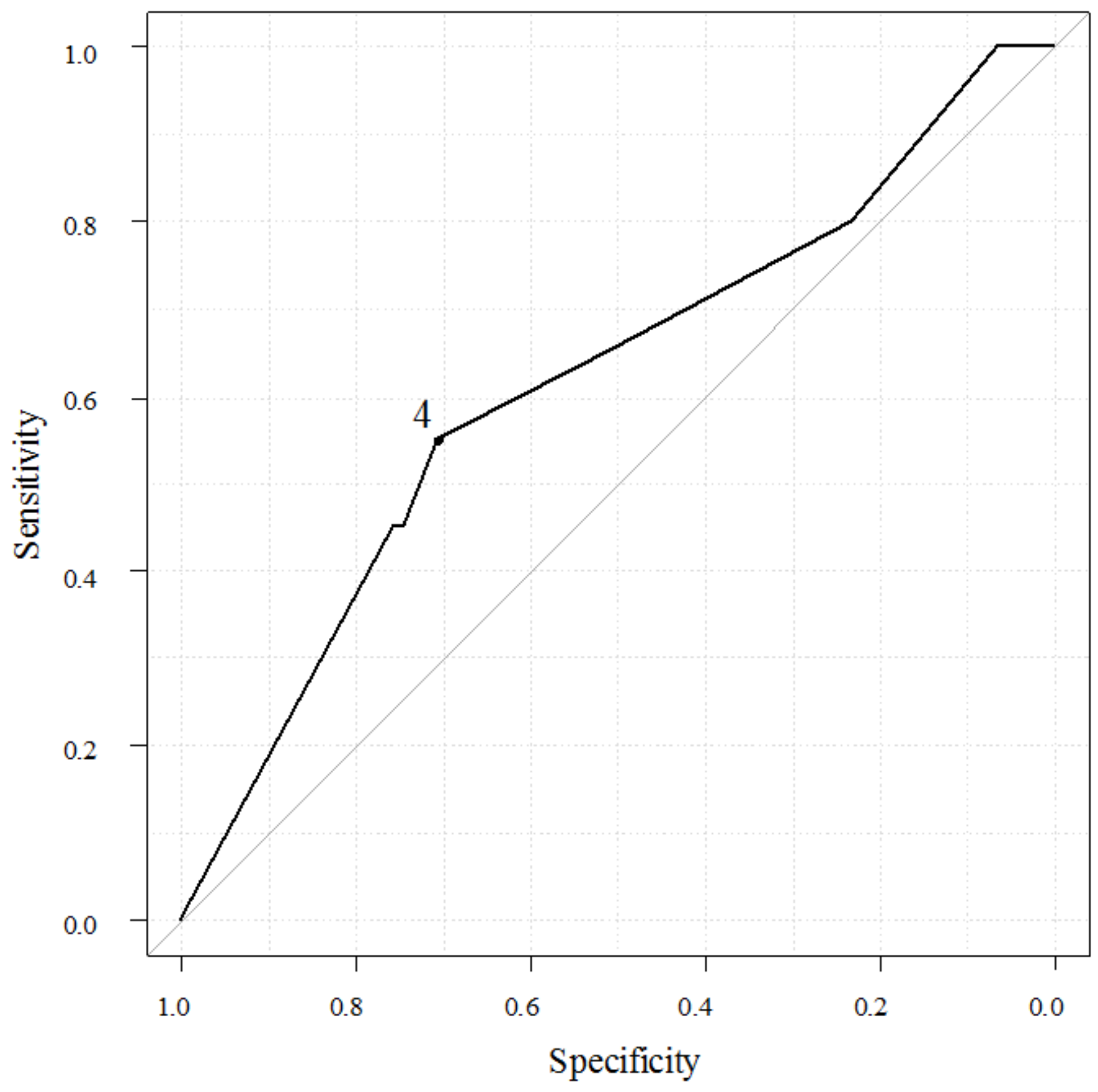

Figure 2

Receiver-operating curve analysis for evaluating the value of the baseline dose of methotrexate for predicting the development of future fragility fracture. The area under the curve was 0.61 ( $95 \% \mathrm{Cl}: 0.47-$ 0.75). A cutoff value of $4 \mathrm{mg} /$ week was determined by the point closest to the upper left-hand corner of the graph with a sensitivity and specificity of $55.0 \%$ and $70.5 \%$, respectively. 



(c). Number of risk factors

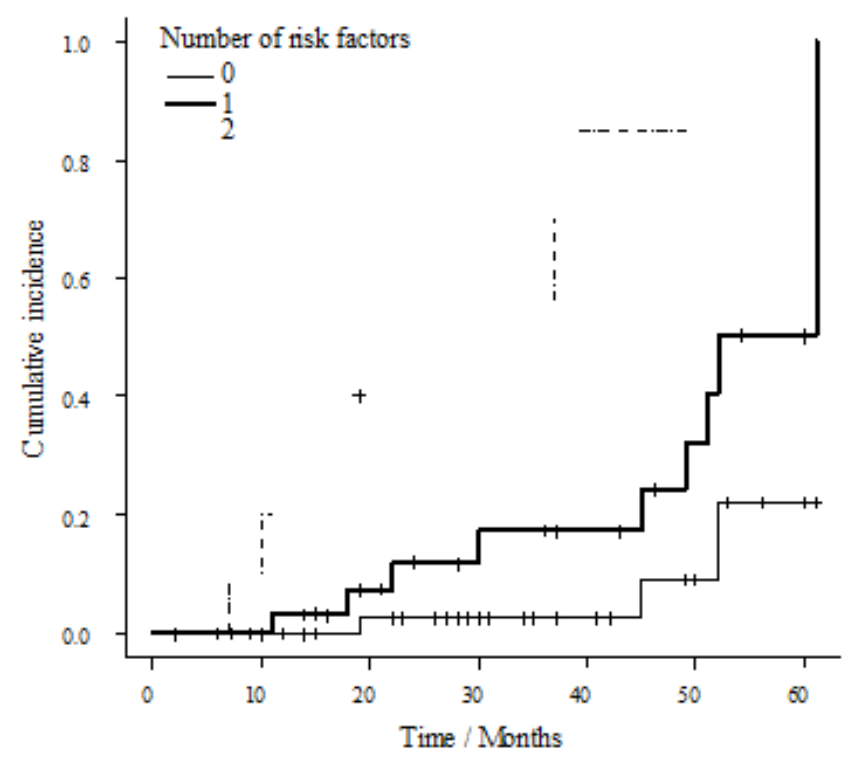

\section{Figure 3}

Cumulative incidence curve for the endpoint defined as the development of any fragility fractures in patients with or without predictors. (a). History of prior vertebral fracture. (b). Dose of methotrexate. (c). Number of risk factors. The dose of methotrexate was divided into two groups, $>4$ or $\leq 4 \mathrm{mg} /$ week, based on the results of the receiver-operating characteristic curve analysis. Risk factors included a history of prior vertebral fracture and $\leq 4 \mathrm{mg} /$ week dose of methotrexate. 